\title{
OCCupational LeAd toxicity in Craft Potters
}

\author{
Nadia Chaouali, Anouar Nouioui, Manel Aouard, Dorra Amira and Abderazek Hedhili \\ Department of Toxicology, Center of Medical Assistance and Emergency “Mahmoud Yaacoub”, Tunis, Tunisia \\ Corresponding author: Nadia Chaouali \\ chaoualinadia@gmail.com
}

(Received 10 October 2017 - Accepted 7 December 2017)

\begin{abstract}
Chaouali, Nadia, Anouar Nouioui, Manel Aouard, Dorra Amira and Abderazek Hedhili. 2018. Occupational lead toxicity in craft potters. Lebanese Science Journal, 19(1): 105-111.

Lead intoxication risks were studied in a community of ceramic folk art workers in Nabeul (Tunisia), where the manufacture of low temperature lead ceramic ware is a family tradition and often the only source of income. Data on lifestyle, working conditions and clinical disorders were collected from workers. 31 potters working in five different workshops were included in this study. Blood lead levels were analyzed by graphite furnace atomic absorption spectrometry. Blood lead levels ranged from 40 to $540 \mu \mathrm{g} / \mathrm{L}$, with a mean of $220.3 \mu \mathrm{g} / \mathrm{L}$. 42 percent of potters had a blood lead level over $200 \mu \mathrm{g} / \mathrm{L}$ and $13 \%$ over $400 \mu \mathrm{g} / \mathrm{L}$, which is over the World Health Organization guidelines for removing workers from exposure, as this is the concentration over which renal damage is accelerated. In the community of ceramic folk art workers living in north-eastern Tunisia, blood lead concentrations were significantly higher $(p<0.05)$. Our findings showed that the use of lead-oxide glaze can increase the risk of lead toxicity and reiterate the need for strict guidelines regarding the use of lead in pottery and replacing it by lead free paints.
\end{abstract}

Keywords: Lead poisoning, pottery, atomic absorption spectrometry.

\section{INTRODUCTION}

Saturnism is an old but serious public health problem that should not be underestimated, and it is the first professionnal disease in Tunisia. Many populations in Tunisia are totally or partially economically dependent upon the ceramic industry, in which lead-oxide glaze is commonly used.

Ceramic artists make use of dyes that contains lead for decades, in covering the surface of ceramic dishes (Hernandez-Serrato et al., 2003). When used in a glaze, lead gives a smooth, glasslike finish that allows bright colors and decorative patterns underneath to show through (Azcona-Cruz et al., 2000). It provides strength and keeps moisture from penetrating into the dish. In decorations, lead is often associated with rich or intense colors (Hibbert et al,. 1999).

The ceramic work and furnace are both located in small settlements, where sanitary services are minimal.Women and children workers are at risk as they most often paint, finish, and glaze the pottery with lead oxides. The mixture contains $80 \%$ lead oxide and $20 \%$ water, to produce the desired glazed finish. The risk for inhalation or ingestion of lead oxide begins during the preparation of the enamel and throughout its application. Moreover, the skin of the potter is in direct contact with the lead mixture (Laraqui et al., 2000). Furthermore, the baking process that sets the enamel releases significant amount of lead to the atmosphere. In addition, some studies have suggested that this may be the source of increased lead exposure in children who simply live in areas occupied by many ceramic workshops (Schnaas, 2004). The aim of this study was to investigate lead poisoning risks in a community of ceramic folk art workers in Nabeul, north-eastern Tunisia, where the manufacture of low temperature lead ceramic ware is a family tradition and often the only source of income.

http://dx.doi.org/10.22453/LSJ-019.1.105-111 National Council for Scientific Research - Lebanon 2018@ lsj.cnrs.edu.lb/vol-19-no-1-2018/ 


\section{Study populations}

\section{MATERIALS AND METHODS}

A cross-sectional study was conducted in the industrial area of Nabeul (Tunisia), with 31 ceramic folk art workers included in this study, and were selected from five different pottery workshops. Data was collected by direct personal interviews, and after getting signed informed consent and providing information on study objectives, procedures and implications to participants. A structured questionnaire examining demographic, environmental, occupational, and food-related variables was given to each participant. In the same visit, a blood and urine samples were obtained from each participant. Blood lead level is considered the best indicator for the degree of actual exposure (Mañay et al., 2008). 5ml of blood sample was collected by venopuncture using a vacutainer containing anticoagulant EDTA K3 (ethylene diamine teraacetic acid). Fresh morning urine was collected in clean containers. 31 healthy volunteers (controls) living in a rural region and not occupationally exposed to lead salts, were also included in the study. Samples were refrigerated at $4^{\circ} \mathrm{C}$ until analysis.

\section{Blood and urine lead measurement}

To eliminate external lead contamination, all glassware and plastic materials, were immersed for several hours in 3\% nitric acid and then thoroughly rinsed with deionized water. All analyses were performed using atomic absorption spectrophotometry (Shimadzu AA-680) with deuterium background correction, equipped with a transversely heated graphite tube atomizer (GFA-4B).

\section{Analysis conditions}

Graphite furnace atomic absorption spectrophotometry (GFAAS) is a useful tool for studying trace metals because it is highly accurate, sensitive, and selective (Zhong et al., 2016). High purity argon (99.999\%) was supplied as the protective and purge gas. The detection limit was of $1 \mu \mathrm{g} / \mathrm{L}$. Blood and urine lead measurement was investigated by the standard addition method. The analytical working solutions included the following: $0 \mathrm{mg} / \mathrm{L}, 10.0$ $\mathrm{mg} / \mathrm{L}, 20.0 \mathrm{mg} / \mathrm{L}, 40.0 \mathrm{mg} / \mathrm{L}$ and $60.0 \mathrm{mg} / \mathrm{L}$, for lead $(\mathrm{Pb})$. Matrix modifiers are widely employed in heavy metal analysis with GFAAS because they can improve the thermal stability of the analytes and reduce the matrix interference by facilitating the volatilization of the sample matrix in the graphite tube (Rego et al., 2012). The matrix modifier used was a mixture of $(\mathrm{NH} 4)_{2} \mathrm{HPO}_{4}(0.2 \%)+$ Triton $\mathrm{X}-100(0.5 \%)+\mathrm{HNO}_{3}(0.1 \%)$.

\section{Statistical Analysis}

Data from the interviews were summarized in descriptive statistics. For the statistical analysis, we used Pearson chi-square exact probability to compare frequencies of sex and age between potters and subjects who were not exposed to lead (controls). We used $t$-tests for independent groups to determine differences in blood lead concentration between potters and those with professions unrelated to lead exposure and were significantly different from each other. Statistical significance was assigned at a P-value $<0.05$. Associations between blood and urine lead levels for each group of workers (potters and nonpotters) were investigated by the use of the Pearson correlation coefficient. Statistical analysis was performed using SPSS package, version 18.

\section{RESULTS}

\section{Epidemiological aspects}

In this population of 31 potters, the majority were men $(77.5 \%)$. The sex ratio of female:male workers was 0.3 . The average age was $35.6 \pm 11$ years. $58 \%$ were between ages 30 and 40 years and $35 \%$ were involved in pottery production. $58 \%$ were occupationally exposed to lead salt over a 10 years period.

\section{Blood and urine lead levels}

Blood lead levels ranged from 40 to $540 \mu \mathrm{g} / \mathrm{L}$, with a mean of $220 \pm 130 \mu \mathrm{g} / \mathrm{L}$. 42 percent of potters had a blood lead level over $200 \mu \mathrm{g} / \mathrm{L}$ and $13 \%$ over $400 \mu \mathrm{g} / \mathrm{L}$, which is over the World Health Organization guideline for removing workers from exposure and is the concentration over which renal damage is accelerated. There was no 
significant trend in blood levels according to age. Mean duration of employment in the ceramic workshop was 12.6 years.

Table 1 illustrates the significant difference between potters and nonpotters, although both groups display a normal distribution of blood lead levels (BLL).

Table 1. Blood lead level of potters and non-potters in the study area.

\begin{tabular}{|c|c|c|c|c|}
\hline \multicolumn{2}{|l|}{ Description } & $\begin{array}{l}\text { Blood lead level }(\mu \mathrm{g} / \mathrm{l}) \\
\text { Potters }\end{array}$ & $\begin{array}{l}\text { Blood lead level }(\mu \mathrm{g} / \mathrm{l}) \\
\text { Non-potters }\end{array}$ & $P$ value \\
\hline \multicolumn{2}{|l|}{ Male } & $210.23 \pm 42.12$ & $87.68 \pm 54$ & \multirow[t]{2}{*}{$0.401^{\mathrm{a}}$} \\
\hline \multicolumn{2}{|l|}{ Female } & $254.52 \pm 45.32$ & $99.3 \pm 48$ & \\
\hline \multirow{4}{*}{$\begin{array}{l}\text { Age range } \\
\text { (years) }\end{array}$} & $<30$ & $119.54 \pm 23.5$ & $64.23 \pm 23.1$ & \multirow{4}{*}{$<0.0005^{\mathrm{b}}$} \\
\hline & $30-40$ & $235.04 \pm 36.5$ & $56.12 \pm 12.6$ & \\
\hline & $40-50$ & $130.18 \pm 42.2$ & $82.45 \pm 12.8$ & \\
\hline & $>50$ & $178.62 \pm 12.4$ & $78.62 \pm 32.7$ & \\
\hline \multirow[t]{2}{*}{ Job duration } & $<10$ (years) & $204.48 \pm 41.6$ & - & \multirow[t]{2}{*}{-} \\
\hline & $\geq 10$ (years) & $250.65 \pm 14.7$ & - & \\
\hline \multirow{2}{*}{$\begin{array}{l}\text { Hours of work per } \\
\text { day }\end{array}$} & $<8$ hours & $142.85 \pm 12.7$ & - & \multirow[t]{2}{*}{-} \\
\hline & $\geq 8$ hours & $253.47 \pm 10.3$ & - & \\
\hline
\end{tabular}

$a$ : Pearson chi-square exact probability

$b: t$-tests for independent groups

Among female workers, one pregnant woman (at the 8th month of pregnancy) was revealed by the questionnaire. Her blood lead level $(360 \mu \mathrm{g} / \mathrm{l})$ was over the WHO guideline for women of childbearing age assigned at $300 \mu \mathrm{g} / \mathrm{l}$. This high level may be attributed to the fact that she was smashing the enamel with bare hands, inspite the fact that regulations prohibits the assignment of pregnant women to such job (Gardella, 2001).

\section{Working conditions}

Data about work characteristics and environment were collected by means of direct observation. In the five pottery manufacturers, the general working conditions were poor. In the five workshops visited, the process of pottery manufacturing was basically made up of the following steps:

First, the components (clay, kaolin...) were bonded into a paste by grinding, mixing and fusing with each other; second, the paste was molded manually and the pieces were dried by passing through a stove and then the piece was dipped into a glaze bath which covers it completely. Third, the pieces were baked under high temperatures resulting in hard colored pieces with a vitreous surface, then the pieces were decorated by manual paintings. A significant relationship was found between blood lead levels and the position held by each worker (Table 2). 
Table 2. Blood lead levels of workers based on the nature of their job in the pottery.

\begin{tabular}{|c|c|c|c|c|}
\hline Position held & Number of patients & Sex & Mean age (Years) & Bll $(\mu \mathrm{g} / \mathrm{l})$ \\
\hline \multirow{2}{*}{ Packaging } & \multirow{2}{*}{3} & 3 men & \multirow[t]{2}{*}{$24.33 \pm 9.45$} & $183 \pm 12.3$ \\
\hline & & 0 women & & - \\
\hline \multirow{2}{*}{$\begin{array}{l}\text { Enameling, glazing and } \\
\text { baking }\end{array}$} & \multirow{2}{*}{12} & 12 male & \multirow[t]{2}{*}{$35.16 \pm 7.30$} & \multirow[b]{2}{*}{$354 \pm 44.6$} \\
\hline & & 0 women & & \\
\hline \multirow{2}{*}{ Manual molding } & \multirow{2}{*}{8} & 7 men & $32 \pm 8.48$ & $148 \pm 17.5$ \\
\hline & & 1 women & 41 & 125.36 \\
\hline \multirow{2}{*}{ Painting } & \multirow{2}{*}{6} & 1 men & 53 & 157.5 \\
\hline & & 5 women & $32.4 \pm 6.5$ & $178.26 \pm 25.2$ \\
\hline \multirow{2}{*}{ Secretariate } & \multirow{2}{*}{2} & 0 men & - & - \\
\hline & & 2 women & $44 \pm 2.82$ & $100 \pm 9.7$ \\
\hline
\end{tabular}

The ceramic work and furnace are both located in the same location which led to a raised temperature in addition to the lack of ventilation. Activities in manual molding were performed without any personnal protective equipment (gloves or respiratory protection), the skin of the potter is in direct contact with the glazing lead mixture. In addition, the baking process that sets the enamel releases significant amount of atmospheric lead. 94\% of the workers remained exposed to high levels of lead without any individual or collective protection. Among the 31 potters, 74\% work without workwear and return home with their contaminated clothing as there is no shower in the workplace. $78 \%$ attested that they eat their lunch at the workshop.

\section{Symptoms of lead poisoning}

Lead is deemed to be toxic, and exposure to lead salts even briefly, or presence of these in the human body even in small amounts can cause severe adverse symptoms (Laraqui, 2000). Even at low levels, it can affect multiple clinical functions (Mañay et al,.2008). This study detected serious adverse effects on potters, occupationally exposed to lead. Figure 1 highlight different clinical disorders reported by potters. 


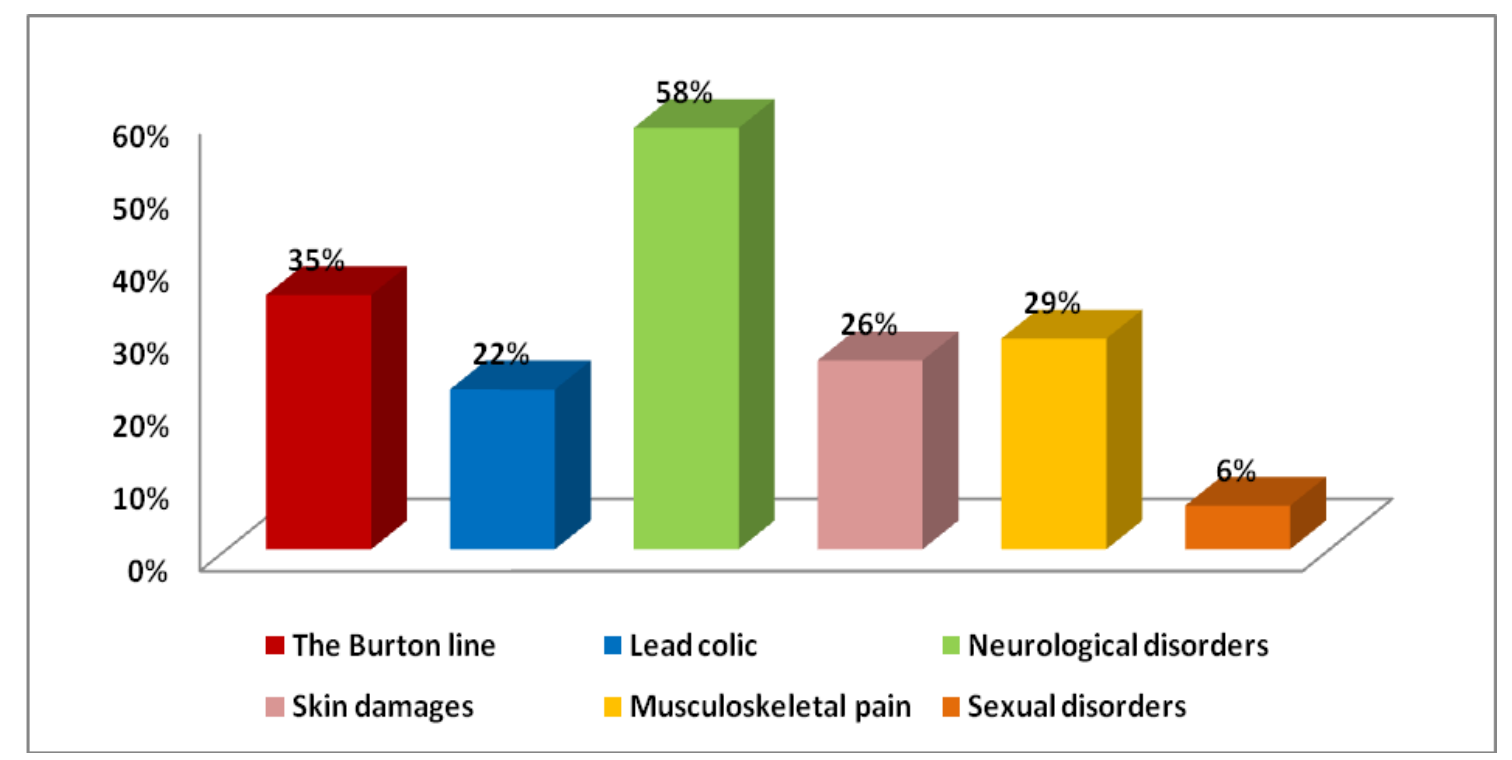

Figure 1. Lead poisoning symptoms reported by potters.

The main clinical disorders detected were neurological (58\%), such as headache, insomnia, memory and concentration disorders, followed by the Burton line (35\%) and lead colic (22\%) represented in stomach cramps and constipation. 6\% attested that they experienced erection disorder and testicular pain. A $29 \%$ prevalence of musculoskeletal pain was found. The most affected locations were lower limbs, neck and shoulders. $26 \%$ reported having experienced atopic dermatitis, pruritus and psoriasis.

\section{DISCUSSION}

Blood lead levels of non-potters (not occupationally exposed to lead salts) were below the World Health Organization guideline of $100 \mu \mathrm{g} / \mathrm{L}$, with a mean of $95 \mu \mathrm{g} / \mathrm{L}$. However this mean was relatively high compared with a French study which found that blood lead levels in French adults was around $30 \mu \mathrm{g} / \mathrm{L}$ (Fréry et al., 2010). Lead exposure can occur through drinking water, smoking or inhaling contaminated air, apart from the occupational sources (Hsu and Guo , 2002). Many cases and sources of lead poisoning have been all over the country which demonstrates that the presence of this element is almost ubiquitous (Valko et al., 2005). Previous studies have demonstrated that tobacco smoking has been shown to increase lead exposure, probably because of lead-containing pesticides (Hernandez et al., 1991). Lead pollution from vehicle exhausts cannot be overlooked (Trzcinka et al,. 2006). In addition, our study detected the average lead levels to be significantly higher in females $(99.3 \pm 48 \mu \mathrm{g} / \mathrm{L})$ as compared to males $(87.69 \pm 54 \mu \mathrm{g} / \mathrm{L})$ across all age-groups. This may be related to women's susceptibility to have iron deficiency (menstruation and pregnancy) which increase digestive absorption of lead (Kaminsky et al., 1993). These results are in contrast with the findings of Labat et al.(2007) who reported that blood and urine lead levels were higher in men than those detected in women.

In the community of ceramic folk art workers living in the north-eastern region of Tunisia, blood lead concentrations were significantly higher overall in potters $(\mathrm{p}<0.05)$. More disquieting is that the World Health Organization considers blood lead concentrations greater than $400 \mu \mathrm{g} / \mathrm{L}$ to be the guideline for removing workers from exposure, and this study revealed that $13 \%$ of this population have levels above this limit, with an average lead blood concentration of $220 \pm 130 \mu \mathrm{g} / \mathrm{l}$. The main determinants of blood lead levels were the use of lead-oxide glaze in the glazing and the decoration of dishes. This emphasizes the public health importance of investigating lead glazed pottery in Tunisia and highlights the benefits expected by adhering to the regulation of the lead content in pottery production. Exposure appears to be primarily associated with antiquated pottery manufacturing techniques and the high degree of contamination prevailing at the production sites, which in most cases are their living quarters 
(Hernandez et al., 2001). However, it was noticed that Tunisian potters were less exposed to lead than Moroccan and Iranian potters. A moroccan study concerning 290 ceramics workers revealed that 80 percent of potters had a blood lead level over the World Health Organization guideline $(400 \mu \mathrm{g} / \mathrm{l})$ and 51 percent over the danger threshold (700 $\mu \mathrm{g} / \mathrm{l}$ ) (Laraqui et al., 2000). Balali et al (2010), reported that Iranians working in the production of tiles (glazed brick) were seriously threatened by lead poisoning, with blood lead levels ranged from $50 \mu \mathrm{g} / \mathrm{L}$ to $680 \mu \mathrm{g} / \mathrm{L}$, with a mean of $520 \pm 35.6 \mu \mathrm{g} / \mathrm{l}$. Since lead has no biological function, there are no safe levels as its presence can cause multiple irreversible damage (Kalahasthi et al., 2014). According to guidelines issued by the Center for Disease Control and Prevention (CDC), blood lead levels of above $100 \mu \mathrm{g} / \mathrm{L}$ is to be considered a cause for concern and should be treated (Sandhya et al., 2015).

Prolonged or repeated exposure to lead salts (more than 10 hours a day) is thought to increase clinical manifestations, most often occurring with blood lead concentrations greater than $400 \mu \mathrm{g} / \mathrm{l}$ (Jaishankar et al., 2014). Neurological disorders were the main clinical disorder detected in potters $(58 \%)$. Studies have shown that low levels of lead affect the nervous system causing behavioral changes, affecting concentration and cognitive functions (TellezRojo et al., 2006). Both the central and the peripheral nervous system are affected by lead causing progressive degeneration of certain parts of the brain symptomized by irritability, poor attention span, headache, loss of memory and hallucinations (Sandhya et al., 2015). We did not detect any case of encephalopathy because blood lead levels were less than $2000 \mu \mathrm{g} / \mathrm{l}$ (Sanders et al,.2009). Twenty nine percent potters experienced musculoskeletal disorders. Repetition, tool use, lack of control over decisions, worries regarding work demands, were all associated with pain. Burton's line is a very thin, bluish-purple line that is found in person's gums as a clinical indicator of lead poisoning. It sits at the junction of the teeth and gums, and it usually covers the distance of two or more teeth. The line is caused by lead sulfide, which is created by the extra lead in the body reacting with sulfur ions that are released by bacteria in the mouth. Although the line is a very good indicator of lead poisoning, it does not appear in every case, making it a useful diagnostic tool, but not a definitive one (Jaishankar et al., 2014). Melzer et al. (2010) concluded that musculoskeletal pain is one of the outcomes of elevated human requirements resulting from working conditions and management in the ceramic worhshops (Fjell et al,.2007). Skin damage seen in $26 \%$ of workers is related to direct contact (bare hands) with the enamel when applied to the ceramic.

The findings of this study showed that the use of lead-oxide glaze can be a risk for lead toxicity and it reiterate the necessity for strict guidelines pertaining the usage of lead in pottery by promoting the use of lead free paints. The effects of lead can be nonspecific, subtle, and delayed and can easily be attributed to other causes. It is important that federal authorities recognize the importance of strict enforcement of existing regulations to eliminate this source of exposure. Stringent personal hygiene, awareness of hazardous materials, and appropriate safety measures may reduce the health risks of repeated exposures. Awareness about lead toxicity as a severe health condition needs to be advertised and a clear road map to handle and manage the situation need to be adopted. In addition, there is a need for more extensive screening of the population to better estimate the magnitude of the problem at the country level. Adverse health effects may be prevented by using less hazardous materials (such as lead-free glazes).

\section{REFERENCES}

Azcona-Cruz, M. Rothenberg, S. Schnaas, L. Zamora-Munoz, J. Romero-Placeres, M. 2000.Lead-glazed ceramic wareand blood lead levels of children in the city of Oaxaca, Mexico. Archives of Environnemental Health, 55: $217-222$.

Balali-Mood, M., Shademanfar, S., Moghadam, J. R., Afshari, R., Ghassemi, M. and Nemati, H. A. 2010. Occupational lead poisoning in workers of traditional tile factories in Mashhad, Northeast of Iran. International Journal of Occupational Medicine and Environmental, 1: 1-5.

Fjell, Y., Alexanderson, K., Karlqvist, L. and Bildt, C. 2007. Self-reported musculoskeletal pain and working conditions among employees in the Swedish public sector. Work, 28: 33-46.

Fréry, N., Saoudi, A., Garnier, R., Zeghnoun, A., Falq, G. and Guldner, L. 2010. Exposure of the French population to environmental pollutant-environmental components of the French national survey on nutrition and health, initial result. French Institute for Public Health Surveillance, $12 \mathrm{pp}$.

Gardella, C. 2001. Lead exposure in pregnancy: a review of the literature and argument for routine prenatal screening, Obstetrical and Gynecological Survey, 56: 231-38. 
Hernandez Avila, M., Romieu, I., Rios, C., Rivero, A. and Palazuelos, E. 1991. Lead glazed ceramics as major determinants of blood lead levels in Mexican women. Environmental Health Perspectives, 94: 117-120.

Hernandez-Serrato, M., Mendoza-Alvarado, L., Rojas-Martınez, R., Gonzalez-Garza, C., Hulme, J. and MolaizFernandez, G. 2003. Factors associated with lead exposure in Oaxaca, Mexico. Journal of Exposure Analysis and Environmental Epidemiology, 13: 341-347.

Hibbert, R., Bai, Z., Navia, J., Kammen, D. and Zhang, J. 1999. High lead exposures resulting from pottery production in a village in Michoacan State, Mexico. Journal of Exposure Science and Environmental Epidemiology, 9:343-351.

Hsu, P.C. and Guo, Y. L. 2002. Antioxidant nutrients and lead toxicity. Toxicology, 180: 33-44.

Jaishankar, M., Tseten, T., Anbalagan, N., Mathew, B. B. and Beeregowda, K.N. 2014. Toxicity, mechanism and health effects of some heavy metals. Interdisciplinary Toxicology, 7: 60-72.

Kalahasthi, R., Barman, T. and Rajmohan, H. 2014. The relationship between blood lead levels and morbidities among workers employed in a factory manufacturing lead-acid storage battery. International Journal of Environmental Health Research, 24: 246-55.

Kaminsky, P., Kein, M. et Duc, M. 1993. Physiopathologie de l'intoxication par le plomb inorganique. Revue de Medecine Interne, 14: 163-170.

Labat, L. and Lhermitte, M. 2007.Sources, exploration et prise en charge de l'intoxication par le plomb.Revue Francophone des Laboratoires, $390: 45-49$

Laraqui, C. H., Caubet, A., Laraqui, O., Rahhali, A., Curtes, J. P. et Verger, C. 2000. Etudes des risques professionnels chez les potiers au Maroc. Cahiers d'étude et de recherche francophones-santé, 10: 249-54.

Mañay, N., Cousillas, A. Z., Alvarez, C. and Heller, T. 2008. Lead contamination in Uruguay: the "La Teja" neighborhood case. Reviews of Environmental Contamination and Toxicology, 195: 93-115

Melzer, A. and Iguti, A. M. 2010. Working conditions and musculoskeletal pain among Brazilian pottery workers. Cadernos de Saúde Pública, 26: 492-502.

Rego, J. F., Virgilio, A., Nobrega, J. and Neto, J. 2012. Determination of lead in medicinal plants by high-resolution continuum source graphite furnace atomic absorption spectrometry using direct solid sampling. Talanta, 100: $21-26$.

Sanders, T., Liu, Y., Buchner, V. and Tchounwou, P. B. 2009. Neurotoxic effects and biomarkers of lead exposure: A review. Revue of Environmental Health, 24: 15-45.

Sandhya, Iyer, Sengupta, C. and Velumani, A. 2015. Lead toxicity: An overview of prevalence in Indians. Clinica Chimica Acta, 451: 161-164.

Schnaas, L., Rothenberg, S. J., Flores, M. F., Martínez, S., Hernández, C. and Osorio, E. 2004. Blood Lead Secular Trend in a Cohort of Children in Mexico City (1987-2002). Environmental Health Perspectives, 112: $1110-1115$.

Tellez-Rojo, M. M., Bellinger, D. C. and Arroyo-Quiroz, C. 2006. Longitudinal associations between blood lead concentrations lower than $10 \mu \mathrm{g} / \mathrm{dl}$ and neurobehavioral development in environmentally exposed children in Mexico City. Journal of Pediatrics, 118: 323-330.

Trzcinka Ochocka, M., Jakubowski, M. and Nowak, U. 2006. Effectiveness of preventive actions for lead exposed workers: an assessment based on biological monitoring. Medycyna Pracy, 57: 537-542.

Valko, M., Morris, H. and Cronin, M. T. 2005. Metals, toxicity and oxidative stress. Current Medicinal Chemistry, 12: $1161-1208$.

Zhong, W., Ting, R. and Zhao, L. 2016. Determination of Pb (Lead), Cd (Cadmium), Cr (Chromium), Cu (Copper), and $\mathrm{Ni}$ (Nickel) in Chinese tea with high-resolution continuum source graphite furnace atomic absorption spectrometry. Journal of Food and Drug Analysis, 24: 46 -55. 